\title{
Carpe DAM! Make your DAM extraordinary!
}

\section{Dennis L. Pannuto}

specializes in coaching companies and technologists in the design, development and implementation of innovative and practical technologies. He is the former $\mathrm{ClO}$ for BBDO, the third largest global advertising network where he was the principle architect in BBDO's acclaimed Digital Workflow solution. In 2003 and 2004, he led BBDO to be recognized by InformationWeek, the leading weekly trade publication in technology, as one of the top 500 IT Innovators. He has also worked and consulted in the entertainment, publishing and banking industries. He is considered one of the leading authorities in the design of successful digital workflow solutions. He is frequently invited to speak, participate in major events and has been featured in influential publications.

Keywords: digital asset supply chain, digital asset management, benchmark, return on investment, ultimate asset, cognitive technology

Abstract Building a successful DAM solution is grounded in study and preparation - the study of those who have succeeded as well as those who have failed miserably. History is an awesome teacher. In addition, the "Digital Asset Supply Chain" should be carefully mapped out and analyzed to optimize the workflow and seek out cost savings and revenue-generating opportunities. Digital Asset Supply Chain is not limited to supply chain companies; everyone who produces, distributes or receives digital content is part of a Digital Asset Supply Chain. Lastly, don't be afraid to stop and regroup when your DAM is going bad.

Journal of Digital Asset Management (2006) 2, 297-302. doi:10.1057/palgrave.dam.3650050

\section{ARTICLE}

Aha!

Why didn't I think of that!

That makes sense...

NOW, I get it...

Man, I can't believe I wasted all that time and money!

Duh!

The older I get the more I appreciate John Wooden's statement, "Failure to prepare is preparing to fail." Looking back upon my career as a $\mathrm{CIO}$ and as someone who has held various leadership positions throughout the past 20 years, I realize that I've experienced the most success when I've surrounded myself with good advisors and good people to develop strategies and execute an initiative: basically a good team. A team grounded in a common vision, committed to doing the tasks needed to fulfill it and the patience to endure the journey. And the most satisfying times were those where that vision truly brought value to other people's lives and me.

Pretty basic, right? Well, in theory yes; in practice, it's more complicated. I've observed that no matter what you do in life, there are pressures all day long that want to pull you into the prevailing current of mediocrity. Parallel to that current is one that promotes a culture of self that ignores strategies and decisions that benefit the greater good of an organization, a company, or simply, a relationship between two people. There are times when I've compromised principles I believed in and have paid the price. I've been pressured to accommodate a situation against good sense. I've "cast pearls to swine" and put them in charge of projects or people that they didn't truly care about or have the ability to lead. I may not have walked away from a situation when I should have. Or maybe I didn't just stop what I was doing when something wasn't going quite right...just stop...stop.... and assess the situation thoroughly before committing any more time - other people's time.... and more money other people's money. And I, and those who were affected, paid the biggest price.

A good strategy, it seems, has to be the foundation of any successful initiative in life. We hear that in many different flavors and scenarios but see it practiced rarely with sound principles 
and good effect. Now there are many theories on what makes a good strategy and I won't attempt to discuss those now but I believe that all would agree that the development of a good strategy begins with study and preparation.

I love history and I love the history of individual lives the most; autobiographies are my favorite. I love to get inside the person and understand not only what made them successful but also I want to study their pain, their shortcomings and their insecurities everything about them. And I want to understand how they navigated through it all.

I make an effort to study my own successes and shortcomings - the "events" — and the one area I'm learning to study even more intensely: the gap between the events: the area that really sets the stage for the next opportunity's probability for success or failure. All of us experience those gaps and it's the decisions we make there that often determine how quickly we reach the next event. Again, study and preparation seem to be critical. It's those moments between the successes and failures that appear to be the time of most study and preparation by individuals and teams that have achieved their defined success. Abraham Lincoln, a man of perseverance in the shadow of personal and political challenges stated:

"I will study and get ready, and perhaps my chance will come."

Today, we have so much information available to us. One example is Major League Baseball. Players are now watching their previous at bats on Ipods to evaluate their mechanics and the pitcher's delivery of pitches so they can make adjustments in their next at bat. The statistics available to baseball manager about players is awesome, even the time of day that players are the most successful. Information and analysis has evolved the game into maximizing probabilities.

No matter what decision you need to make, the challenge is finding the best information, analyzing it effectively and then acting upon it practically. Other than the salary differences, the study and preparation involved in a DAM is no different than in baseball. The success stories are grounded in study and preparation not only before the implementation of a solution but throughout the life of it.
Building an extraordinary DAM solution takes getting and staying informed. We're going to look at three areas that can be applied:

1. Get insight from the Winners and Losers.

2. Get insight into your Digital Asset Supply Chain.

3. When things aren't going well...Stop! And get a Check-Up

\section{GET INSIGHT FROM THE WINNERS AND THE LOSERS}

When Robin Williams in the movie Dead Poets Society tells his students to "seize the day," he's challenging those young minds to step outside of the normal way of thinking and living. The life of practical mediocrity. He's challenging them to suck the marrow out of life, out of every situation, out of every opportunity and to dare to do and to live extraordinarily...To learn and to live extraordinary lives.

Williams' character, John Keating, an English teacher, says to the young men:

"Now I would like you to step forward over here and peruse some of the faces from the past. You've walked past them many times. I don't think you've really looked at them... They're not that different from you, are they?...Did they wait until it was too late to make from their lives even one iota of what they were capable? Because you see gentlemen, these boys are now fertilizing daffodils. But if you listen real close, you can hear them whisper their legacy to you. Go on, lean in... Carpe...Hear it? Carpe. Carpe Diem. Seize the day, boys. Make your lives extraordinary."

The legacy that John Keating is referring to is what we've done with our lives, with opportunities, with situations... or what we haven't done. It's the good, the bad and everything in between. That is our legacy. It is what we leave behind.

And while some have injected a carpe diem dose to an Epicurean lifestyle and philosophy to being reckless and irresponsible, proclaiming "eat, drink and be merry for tomorrow we die" - that hasn't shown to be fruitful application. Such application is for the lazy, the reckless and the irresponsible. Horace, the great Roman poet, a "carpe diem" enthusiast, said:

"No man ever reached to excellence in any one art or profession without having passed through the slow and painful process of study and preparation." 
Why not do things extraordinarily? Why not do extraordinary DAM?

I rarely speak to someone who raves about what an extraordinary experience they've had with a particular technology, although it does happen. (In fact, computer technologists generally suck at developing technologies that truly enhance the human experience.) When I have though, the users of the technology always talk about how it enhanced their experience, improved their situation and brought value to their life in some way. Hands down, those involved with the creation, design and implementation of that technology made study and preparation the starting point and part of the ongoing process. Not the study of one section of books with all the same Dewey Decimal classification. No. A broad and in-depth study of all the dynamics involved in an implementation, the human and organizational interactions, the true costs, the potential revenue, the available technologies and most important: history. The history of what others have done, the good and the bad and everything in between - reading the case studies, the literature and talking with the people from the programmers to the users, from the CIOs to the CEOs and the experts who genuinely specialize in that particular field.

Simply, study and preparation are the fundamentals of developing something that delivers true value and enhances the human experience.

When I set out on my DAM journey almost 10 years ago, I studied everything I could about what was being done and how it was being done. I traveled and spoke with the integrators; software and hardware manufacturers and those who had successfully developed DAM solutions as well as those who had failed in their attempts. I even went to Berkeley University and spent some time with academics who developed the algorithms and technologies behind information retrieval systems. I established benchmarks by industry and solutions provider and kept a close watch. I pretty much covered it all.

You see, I had a vision of building a system that would catalogue and distribute video, audio and print. Not just archive but one that would truly move digital assets faster while saving the company a considerable amount of money. In theory, I knew it could be done and there were several integrators and software manufacturers who were more than willing to take my money - actually Golden Books' money - to try to build it. But as I dug into the realities of what could be done, I realized that the technology just wasn't ready without making the solution cost prohibitive. I decided, then, to build a model that I would evolve with the maturation of the technologies, and thus deliver a usable system in less than one year. And we did. Although, the dream was cut short because of Golden Books being chopped up and sold off.

By the time I made it to BBDO in 2001, I had done all of the homework required to get a solid system up and running that integrated digital video, audio and print, and a system was developed with a wonderful team that enhanced the human experience, saved the company money and opened the opportunity for new revenue. And it continues to grow today.

Simply, without the study and preparation before, during and after each milestone, success withers.

No doubt that study and preparation can be a slow and painful process. It is one that typically doesn't accommodate capex budget deadlines or management with the attention spans of a toddler. And it doesn't help that IT organizations often cannot be bothered with the amount of time required to understand how people work and how organizations within and without interact with one another; they just want to slam the technology in and then blame the disaster on the users or the vendors.

Change is disruptive. There are right ways and wrong ways to implement change. And it's those individuals who take the time to understand the difference that truly do extraordinary things for the people they affect.

\section{GET INSIGHT INTO YOUR DIGITAL ASSET SUPPLY CHAIN}

I can't think of a better way to truly understand how something works than to take it apart, study each part and then put it back together again. And if you want to make it better, then you need to first understand how it works so you can understand what you need to do to improve the process.

In the world of Digital Asset Management many think of DAM as a final resting place for digital content. I don't consider DAM just an 
archive. I consider it a Digital Workflow or a popular term these days: Digital Asset Supply Chain. It's the process of how a piece of digital content is thought of, produced, distributed and stored.

In broader terms, a digital asset supply chain represents the flow of digital content from the ideation, production, distribution and archive of that content and all of the information associated with that digital content as it travels between various individuals, groups and systems to create a final digital asset. To gain an understanding of true costs and revenue opportunities at the different stages, digital content should be understood within a supply chain model.

So at some point, before making a financial commitment to hardware and software, you're going to have to invest time to understand this Digital Asset Supply Chain. It can be done during or after you're learning everything you can about what it takes to have a successful DAM solution. Either way, it's a critical step that can't be ignored. You might say 'we're not a supply chain business'. You may be right but if you produce, receive or distribute any type of digital content, you are part of a digital asset supply chain and you're probably throwing away more money than you realize.

If you're still uncomfortable about the phrase Digital Asset Supply Chain, you can call it Digital Workflow or Digital Content Lifecycle, or make up a new one. Use whatever it takes to get the message across to the people you are trying to reach.
Ok, why should I care? Because if a DAM solution cannot deliver value to that digital asset supply chain then there isn't a need for one. Then, and only then, can you truly design a successful DAM solution and develop a business case with measurable ROI. You may not even recognize exorbitant costs like duplication and storage of assets because they don't show up in any report and may not hit your profit and lossstatements. You will very likely discover spending habits that you and finance were unaware of. Chances are, you'll look like a star and you'll very likely find the money to fund your DAM by simply eliminating some inefficient processes.

There seems to always be a struggle in determining what digital content should be part of a DAM solution and how it should be managed. What is the most important asset? What version do we keep? What about all this other stuff? 'My Digital Asset Supply Chain seems to be all over the place!' It probably is. One way to get a company focused on the right priorities for organizing their digital content and understanding their Digital Asset Supply Chain is using the Ultimate Asset Model. The Ultimate Asset is the final digital version of the product you produce. It may be a book, a magazine, a brochure, a photograph, music, an ad, TV program or whatever. Basically, the Ultimate Asset is your most valuable piece of digital content.

It has been my experience that the Ultimate Asset Model facilitates a clear method to

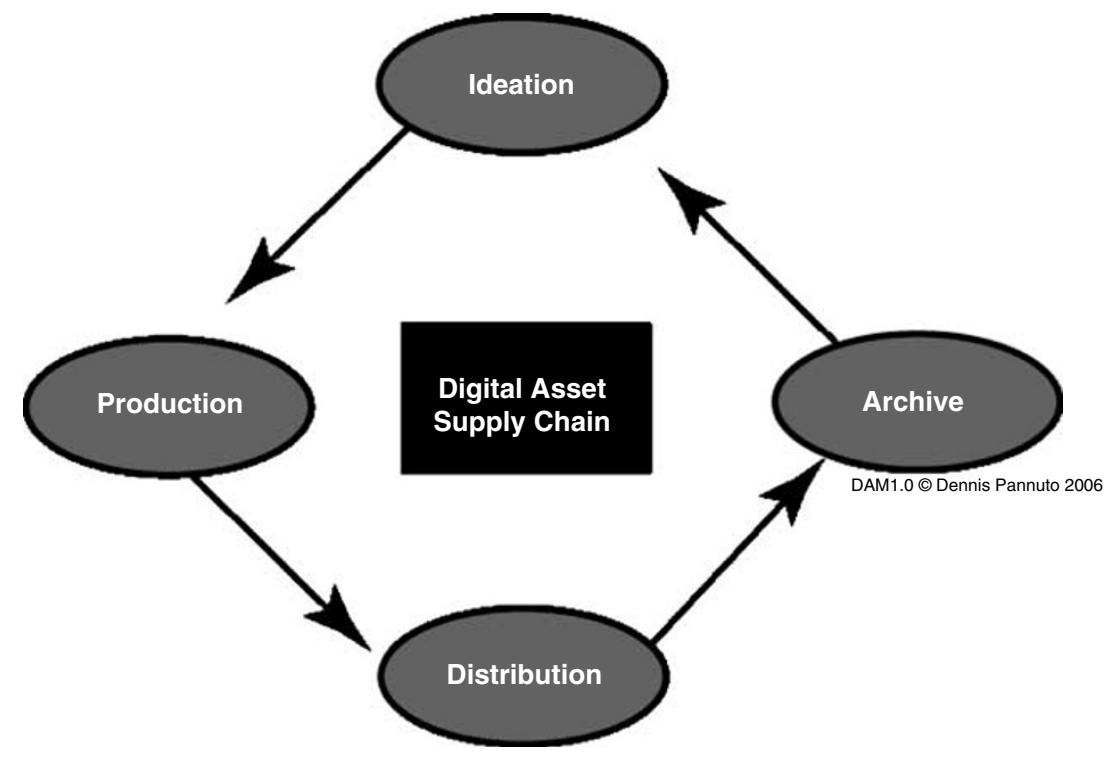


eliminate competing priorities between groups and a metadata model that is too large to manage. It gets everyone focused on where they fall within the Digital Asset Supply Chain. It provides insights how their individual or groups needs can be reasonably met while preserving the integrity of the DAM solution. It provides improved access to key information and faster distribution across all groups while reducing process and cost. It allows finance departments to better understand and manage costs, and technologists can understand what is important to better align technology investments with the value of the digital assets.

For example, why would you want to invest the overhead in technology and administrative function to catalogue content that is rarely used or referred back to just to say you have it stored in a database. One group may want that but it's probably impractical to invest the resource when that group's needs can probably be met using a file-based system or they can have access to the same information at some other point within the Digital Asset Supply Chain

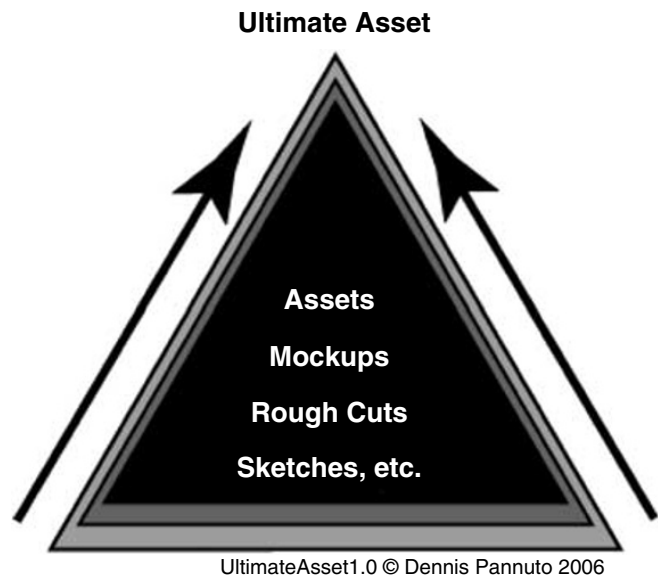

Identifying the Ultimate Asset, mapping out the Digital Asset Supply Chain and analyzing every cost and every interaction is a critical step to develop a DAM solution that becomes a true asset to the company it serves and is able to evolve with the business and the technologies.

When analyzing your Digital Asset Supply Chain, benchmarking the costs and use of technology against your industry and other industries is very important. It provides you with negotiation leverage and an understanding at what technologies are working best in your industry while giving you fresh insights into other industries solutions that you may want to apply.

Many find that getting insight into their Digital Asset Supply Chain can be overwhelming and time-consuming. As a result, it is often not given the necessary attention or objectivity. DAM implementations that do not invest the time into understanding their Digital Asset Supply Chain generally do not deliver value throughout the lifecycle of the asset, miss savings and possible revenue opportunities and often become obsolete when they're not positioned for business changes and the evolution of technology.

There are experts that can rather quickly relative to the length of a DAM implementation - model your digital asset supply chain and help uncover opportunities as well assist in benchmarking. Whether you do it yourself or have someone else do it, it's an investment that will very likely pay for your implementation many times over.

\section{JUST STOP! AND GET A CHECK-UP}

When things aren't going well just stop.

I've been involved in several technology investments that went south because of not following the basic principles I talk about but I've never had a failure where I could ensure a sensible process was maintained. It's not because I'm that smart, no way. It's probably because I was always too afraid to fail so I wanted to make sure I covered all bases. (If only I'd be more consistent in other areas of my life!)

Often the implementations that get off to a bad start are ripe with opportunities to get the implementation on track but executives and project leaders are stuck in an ego-centric umbrella, fueled by fear to fail, which creates a state of denial and they inevitably fall victim to the axiom: "Pride comes before the fall." And fall they always do. Or, sometimes people just can't accept the failure as reality and get stuck in an emotional cage as opposed to making rational decisions. (Many of us got that way when we lost so much money in the internet stock crash and just wouldn't sell the peanuts that were left. I did!) Either way, we get stuck in what I call the Treadmill Syndrome. Simply, the Treadmill Syndrome is working real hard and 
getting nowhere because you're choosing to be stupid. It's insane.

There is an old saying that is attributed to different people. I don't know who said it. Who cares? But it sure makes sense:

"The definition of insanity is doing the same thing over and over again while expecting a different outcome."

In general, men hate to stop and ask for directions when they're lost. Computer technologists rarely like to ask for help. Most computer technologists are men. Now, I've worked with and observed some very bright people make the same mistakes over and over again because of being stuck on that treadmill. How many do you know? Are you one of them? How many DAM implementations do we hear about that sink millions of dollars, go on for years and they keep dumping more time and more money without stopping and analyzing why it sucks? So what if you've failed! Get some help, some fresh perspective. Get back to the basics. Get educated. Some of the most rewarding successes I've had in my career are stopping implementations that I inherited in mid-stream and have gone back to the basics of study and preparation. Sometimes we took several months to regroup before starting again. Sometimes we had to abandon certain investments. But in the end, the company reaped a valuable system - usually in a shorter period of time than they thought was possible. Thomas Edison had a healthy perspective on approaching failures:

"I haven't failed, I've found 10,000 ways that don't work"

Sure, you may have had to fight some people who don't want to be exposed or identified with a failure but if you look to help them and make them part of the solution as opposed to painting them like the scapegoat, you'll very likely be able to gain their support. There will also be others who scream 'Analysis Paralysis!' I've observed that these people usually aren't that bright, have never done anything significant that delivered real value and you should ignore them and focus on doing what's right anyway.

Obviously we all want to avoid pitfalls. Preventive medicine is often a good consideration. You may want to hire an experienced DAM coach who has absolutely no direct affiliation with any of your vendors. This way, they can help guide you through the process and they get paid based on your success.

\section{GET INSIGHT!}

Doing extraordinary things requires doing extraordinary things. It takes balls to step outside of that strong current of mediocrity that turns us into task-oriented people who blindly follow the blind, as opposed to becoming idea-driven people fueled by imagination and led by excellence that betters our lives and those around us.

Doing extraordinary DAM takes study and preparation and the gravitas to do both.

I'll leave you with a wonderful quote from a brilliant man:

"Never regard study as a duty, but as the enviable opportunity to learn to know the liberating influence of beauty in the realm of the spirit for your own personal joy and to the profit of the community to which your later work belongs."

Albert Einstein

Peace. 